\title{
Effect of posterior surgery on pre- and post-operative sports activity in patients with adolescent idiopathic scoliosis
}

Takehide Katogi ${ }^{1^{*}}$, Toshiaki Kotani ${ }^{2}$, Jose Miguel T Lumawig ${ }^{3}$, Maiko Sano $^{1}$, Tsutomu Akazawa ${ }^{2}$, Tsuyoshi Sakuma², Shouhei Minami²

From The 10th Meeting of the International Research Society of Spinal Deformities (IRSSD 2014 Sapporo) Sapporo, Japan. 29 June - 2 July 2014

\section{Background and purpose}

Very few papers have been published on the influence of scoliosis surgery on sports activity. The purpose of this study is to analyze the impact of surgery on sports activity in patients with Adolescent Idiopathic Scoliosis (AIS).

\section{Materials and method}

Among the patients with AIS who underwent surgery in our institution, 15 patients were analyzed. Minimum follow up period post-surgery was 2 years. Patients were all females with an average follow-up of 38 months. The mean patient age at surgery was $14.2 \pm 1.5$ mean Cobb angle of the major curve preoperatively was $54.3 \pm 7.4$ and $21.8 \pm 6.9$ degrees postoperatively. We evaluated the strength, speed and agility of these patients pre- and postoperatively using the government-prescribed Physical Fitness Test.

\section{Results}

Postoperatively, general performance in the Physical Fitness Test improved for 4 patients, remained stable for 10 patients and decreased for 1 patient. There were no significant differences seen for the individual physical fitness tests done for these patients pre-and postoperatively $(\mathrm{p}<0.05)$.

\section{Conclusion}

Posterior surgery for AIS did not influence the strength, speed and agility of the patients at an average follow up of 38 months post surgery.

${ }^{1}$ Seirei Sakura Citizen Hospital, Chiba, Japan

Full list of author information is available at the end of the article

\section{Authors' details}

${ }^{1}$ Seirei Sakura Citizen Hospital, Chiba, Japan. ${ }^{2}$ Seirei Sakura Citizen Hospital Department of Orthopedic Surgery, Chiba, Japan. ${ }^{3}$ St.Luke's Medical Center,

Taguig, Philippines.

Published: 19 January 2015

doi:10.1186/1748-7161-10-S1-031

Cite this article as: Katogi et al.: Effect of posterior surgery on pre- and post-operative sports activity in patients with adolescent idiopathic scoliosis. Scoliosis 2015 10(Suppl 1):O31.
Submit your next manuscript to BioMed Central and take full advantage of:

- Convenient online submission

- Thorough peer review

- No space constraints or color figure charges

- Immediate publication on acceptance

- Inclusion in PubMed, CAS, Scopus and Google Scholar

- Research which is freely available for redistribution
( Biomed Central 